\title{
Turbulent acidic jets and plumes injected into an alkaline environment
}

\author{
H. Ülpre, I. Eames† and A. Greig \\ Department of Mechanical Engineering, University College London, Torrington Place, \\ London WC1E 7JE, United Kingdom
}

(Received 19 December 2012; revised 27 August 2013; accepted 9 September 2013; first published online 8 October 2013)

The characteristics of an acidic turbulent jet and plume injected into an alkaline environment are examined theoretically and experimentally. Fluid-flow and chemistry models are combined to understand how the concentration of acid in a parcel of fluid changes as it reacts with alkaline fluid entrained from the ambient. The resulting model is tested in an experimental study in which nitric acid jets or plumes are injected into a large tank containing a variety of alkaline substances. A video camera records a $\mathrm{pH}$-sensitive dye in the jet or plume, which changes colour with variations in the $\mathrm{pH}$. The results were time averaged and processed to measure distance from the source to the point of neutralization. The agreement between predictions and observations of neutralization distances is good, confirming that the model captures the salient physics of the problem. Using empirically determined titration curves, a combined fluid flow and chemistry model is applied to discuss the environmental implications of a warm acidic turbulent plume injected into an alkaline river or sea.

Key words: jets, plumes/thermals, turbulent reacting flows

\section{Introduction}

The combustion of fossil fuels results in the production of polluting byproducts such as carbon oxides $\left(\mathrm{CO}_{x}\right)$ and soot (carbon particles), both of which have harmful effects on the environment. Carbon oxides are major contributors to ocean acidification (Raven et al. 2005). Soot has a long airborne residence time that has been proven to be detrimental to human health (Jacobson 2010) and it also reduces the reflection coefficient of snow and ice, raising their melting point (Hansen \& Nazarenko 2004).

Depending on the type of engine and fuel used, nitrogen oxides $\left(\mathrm{NO}_{x}\right)$ and sulphur oxides $\left(\mathrm{SO}_{x}\right)$ may also be present in exhaust gases. One source of nitric oxides is combustion at high temperatures. The release of nitric oxides can be mitigated through a number of methods inside and outside of the engine (Blatcher \& Eames 2013). Sulphur is naturally present in fossil fuels, but its quantity depends on the originating region and fuel type. At a significant cost fuel sulphur content can be reduced by refining. Sulphur and nitrogen oxides in the atmosphere form either wet 
precipitates (acid rain, snow and fog) or dry precipitates (acidic gases and salts). These precipitates affect the acid-alkali balance of freshwater systems, in which $\mathrm{pH}$ recovery to original levels takes a long time because of reduced concentrations of dissolved alkaline substances (Schindler 1988).

Numerous air pollution control devices mitigate the release of pollutants to satisfy increasingly stringent environmental legislation. In areas where water is abundant (e.g. coastal regions, rivers or estuaries) heavy industries (e.g. mining, chemical and power generation) use wet scrubbers to reduce polluting byproducts in exhaust gases. Wet scrubbers generally work by bringing the exhaust gas into contact with water. The resulting wash-water contains sulphuric $\left(\mathrm{H}_{2} \mathrm{SO}_{4}\right)$ and nitric $\left(\mathrm{HNO}_{3}\right)$ acids, which are formed from the chemical reactions between sulphur and nitrogen oxides and water. The wash-water is then filtered of particulate matter, which is stored in tanks, and the remainder is discharged back into the natural environment. Owing to its high acidity, the wash-water needs to be diluted or treated prior to discharge. Owing to contact with hot exhaust gases, the treated discharge usually takes the form of a warm acidic turbulent plume. The configuration of the scrubber discharge pipe controls the depth, angle and rate of discharge.

Chemistry is a key element to understanding the influence of acidic discharges into the marine environment. The Brønsted-Lowry definition of acids and alkalis (Brønsted 1923; Lowry 1923) states that acids are substances which donate hydrogen ions $\left(\mathrm{H}^{+}\right)$ and alkalis are substances which add hydrogen ions. The $\mathrm{pH}$ scale, introduced by Sørensen (1909), is a measure of concentration of $\mathrm{H}^{+}$or $\mathrm{OH}^{-}$ions on a logarithmic scale. At atmospheric pressure and $25^{\circ} \mathrm{C}$ a solution is considered acidic at $\mathrm{pH}<7$, neutral at $\mathrm{pH}=7$ and alkaline at $\mathrm{pH}>7$. A neutral $\mathrm{pH}$ is temperature dependant and varies from $\mathrm{pH}=7.47$ at $0{ }^{\circ} \mathrm{C}, \mathrm{pH}=7$ at $25^{\circ} \mathrm{C}$ and $\mathrm{pH}=6.92$ at $30{ }^{\circ} \mathrm{C}$. The effect of pressure on $\mathrm{pH}$ is negligible within context of wet scrubber discharges (Kitamura \& Itoh 1987). It is important to note that 'strong' and 'weak' in the context of acids/alkalis refers to their dissociability and not concentration. In solution, strong acids/alkalis dissociate fully into ions $\left(\mathrm{H}^{+}\right.$and the anion, $\mathrm{A}^{+}$, in the case of the acid and $\mathrm{OH}^{-}$and the cation, $\mathrm{M}^{+}$, in the case of the alkali). Weak acids and alkalis dissociate incompletely, the ratio of which at equilibrium is measured by a constant $K_{a}$ for acids and $K_{b}$ for alkalis (Gordus 1985).

Seawater is a weak alkaline buffer solution which contains a large number of dissolved salts (Drever 1988), some of which affect its $\mathrm{pH}$. Alkaline buffer solutions resist changes to $\mathrm{pH}$ by absorbing $\mathrm{H}^{+}$ions when small amounts of strong acid are added. The most important contributors to the buffering capacity of seawater are carbonate $\left(\mathrm{CO}_{3}^{2-}\right)$ and bicarbonate $\left(\mathrm{HCO}_{3}^{-}\right)$ions, which react with $\mathrm{H}^{+}$ions in a reversible reaction to form carbonic acid, which can in turn dissociate to form water and gaseous carbon dioxide (Frankignoulle 1994). Seawater's buffering capacity is also influenced by water temperature, depth, salinity and coastal runoffs. For example, glacial ice melting in the summer introduces freshwater into seawater reducing the acid buffering capacity. The $\mathrm{pH}$ of seawater is always lower at free surface because carbonic acid is produced when the seawater absorbs atmospheric carbon dioxide. The chemical composition of sea and river water also varies geographically. For example, the $\mathrm{pH}$ of seawater in the North Sea varies from a pH of 7.71 in Meyer Werft, River Ems, Paneburg, Germany to a pH of 8.0 in Nassau Harbour, Jade Bay, Wilhelmshaven, Germany (Behrends, Liebezeit \& Hufnagl 2005).

Acids are corrosive and some, such as sulphuric acid, are also toxic to marine life. Bell \& Nebeker (1969) observed that most marine insects seem to be able to tolerate an environment with a $\mathrm{pH}$ of 5 for $96 \mathrm{~h}$. However, survival rates dropped significantly 
when the $\mathrm{pH}$ was reduced to 3 with some species not surviving at all. Trent, Hestand \& Carter (1978) investigated the effects of sulphuric acid on a range of marine animals and plants with exposure times of up to $96 \mathrm{~h}$. It was concluded that with varying mortality rates, most organisms were able to survive in an environment with a $\mathrm{pH}$ of 5 for up to $96 \mathrm{~h}$. However, snails were affected more than other organisms and died rapidly. With the exception of midges and mosquitofish, all of the tested organisms died during a $24 \mathrm{~h}$ exposure period in an environment with a $\mathrm{pH}$ of 3 . In the long term, a reduction in the average $\mathrm{pH}$ of seawater also poses a significant risk to fauna, in particular to calcifying organisms with calcium carbonate shells and skeletons and coral reefs (Raven et al. 2005). Acidic seawater dissolves their defensive properties, making them more vulnerable to predators.

When estimating the impact of scrubber discharge on marine environments, it is important to evaluate how $\mathrm{pH}$ changes with distance from the point of discharge and how long aquatic animals spend in regions of depressed $\mathrm{pH}$. This process depends on dilution due to entrainment of ambient fluid and on acid-alkali reactions between the discharge and seawater. Dilution caused by entrainment at the edge of the jet or plume has been studied in detail over the last 50 years. Nevertheless, there is a debate on the detailed elements of entrainment, such as on the dominance of nibbling versus engulfment (Hunt, Eames \& Westerweel 2006; Hunt et al. 2011). Theoretical models on jets and plumes (List 1982) are usually based on the conceptual framework of Morton, Taylor \& Turner (1956), which has been extended to include the effects of momentum, buoyancy and sources varying in time (Scase, Caulfield \& Dalziel 2006a; Scase et al. 2006b), non-Boussinesq behaviour (Woods 1997) and internal generation of buoyancy (Hunt \& Kaye 2005). A number of studies have also examined the chemistry of reacting jets and plumes. Conroy \& Llewellyn-Smith (2008) analysed second-order irreversible exothermic and endothermic reactions between a point source plume and a second species in the ambient. Campbell \& Cardoso (2010) and Cardoso \& McHugh (2010) examined the influence of internal buoyancy generation through irreversible reactions resulting in phase change on the development of plumes in stratified and unstratified environments. Cardoso \& McHugh (2010) experimentally analysed a plume containing calcium carbonate particles descending in an acidic aqueous solution where the generation of carbon dioxide bubbles on the surface of the particles modified the buoyancy flux of the plume. A number of studies have used acid-alkali reactions combined with $\mathrm{pH}$-sensitive dyes as a visualization tool to examine mixing in jets (Dimotakis \& Brown 1976; Corriveau \& Baines 1993).

The purpose of this paper is to study jet and plume discharges of acidic fluids into alkaline environments. We analyse how the $\mathrm{pH}$ recovers to its original value with distance and how much this process depends on the relative concentration of the acid and alkali. Theoretical models for jets and plumes have been studied in great detail (Woods 2010). However, gaps exist when one examines the chemical reactions between an acidic plume and an alkaline environment. The new aspect of the current analysis is the combination of a fluid model with reversible acid-alkali reactions. In light of the discharge of wash-water from wet scrubbers into seawater, we limit our attention to Boussinesq flows.

The paper is structured as follows: in $\S 2$, we introduce a mathematical model for chemical reactions for an acid being injected into an alkaline environment. In order to provide a basis for testing the predictions, a series of experiments are undertaken and described in $\S 3$. Experimental results are presented and discussed in $\S 4$. In order to apply our analysis to a practical situation we combine empirical titration curves with our model in $\S 5$. The paper is concluded and the findings are summarized in $\S 6$. 


\section{The mathematical model}

An acidic fluid issues with a mean vertical speed of $w_{0}$ from a circular orifice of radius $b_{0}$ into an otherwise stagnant ambient body of water. The injected fluid has a density $\rho_{0}$ and contains a concentration $C_{a}^{0}$ of monoprotic strong acid HA. The ambient fluid has a density $\rho_{a}$ and a concentration $C_{b}^{0}$ of alkali $\mathrm{MOH}$. It is assumed that the issuing fluid is perfectly mixed across the width of the jet or plume. The analysis describes a purely acidic jet or plume injected into a purely alkaline environment. It can be straightforwardly extended to account for alkali in the jet or plume, as indeed we do to interpret experiments and apply analysis to practical situations. We are also assuming that the mixing processes have a far longer time scale than the chemical processes that happen very rapidly on time scales less than $10^{-9} \mathrm{~s}$ (Eigen 1954). For analytical simplicity, our discussion is centred around strong monoprotic acids (e.g. nitric acid) which donate one $\mathrm{H}^{+}$ion per molecule. The limit of the acid being strong is in keeping with the practical context, although ambient fluid may be a weak alkali or dilute strong alkali. The chemistry model is extended for a strong or weak diprotic acid (e.g. sulphuric acid) reacting with a strong or weak monoprotic alkali in the Appendix.

\subsection{Chemistry model}

We first analyse a strong acid and a strong or weak alkali reacting in an aqueous solution. Consider a fixed volume of acidic fluid $V_{a}$ that is being diluted through the addition of alkaline fluid $V_{b}$. The chemical reaction is governed by the conservation of charge

$$
\left[\mathrm{H}^{+}\right]+\left[\mathrm{M}^{+}\right]=\left[\mathrm{OH}^{-}\right]+\left[\mathrm{A}^{-}\right],
$$

and the conservation of mass of alkali and acid respectively

$$
C_{b}^{0} V_{b}=\left([\mathrm{MOH}]+\left[\mathrm{M}^{+}\right]\right)\left(V_{a}+V_{b}\right), \quad C_{a}^{0} V_{a}=\left[\mathrm{A}^{-}\right]\left(V_{a}+V_{b}\right) .
$$

The square brackets denote the molar concentration $\left(\mathrm{mol} \mathrm{l}^{-1}\right)$ of the species. The condition $(2.2 b)$ occurs because the acid is strong and fully dissociates, i.e. $\mathrm{HA} \rightarrow$ $\mathrm{H}^{+}+\mathrm{A}^{-}$. Both water and a weak alkali dissociate reversibly, i.e. $\mathrm{H}_{2} \mathrm{O} \rightleftharpoons \mathrm{H}^{+}+\mathrm{OH}^{-}$ and $\mathrm{MOH} \rightleftharpoons \mathrm{M}^{+}+\mathrm{OH}^{-}$. The dissociation constant of water $K_{w}$ and alkali $K_{b}$ are defined by

$$
K_{w}=\left[\mathrm{OH}^{-}\right]\left[\mathrm{H}^{+}\right], \quad K_{b}=\frac{\left[\mathrm{M}^{+}\right]\left[\mathrm{OH}^{-}\right]}{[\mathrm{MOH}]} .
$$

At $25{ }^{\circ} \mathrm{C}$ and atmospheric pressure, $K_{w}=10^{-14} \mathrm{~mol}^{2} \mathrm{I}^{-2}$. In the standard notation, it is important to note that $K_{w}$ and $K_{b}$ have different units $\left(\mathrm{mol}^{-1}\right)$ to $K_{w}$, see, e.g., Atkins $\&$ De Paula (2006). Combining (2.1), (2.3a) and (2.3b) generates an implicit equation which relates the $\mathrm{H}^{+}$ion concentration to the dilution of the acid by the alkali

$$
\frac{V_{b}}{V_{a}}=\frac{C_{a}^{0}-\left[\mathrm{H}^{+}\right]+K_{w} /\left[\mathrm{H}^{+}\right]}{C_{b}^{0} /\left(1+K_{w} /\left(\left[\mathrm{H}^{+}\right] K_{b}\right)\right)+\left[\mathrm{H}^{+}\right]-K_{w} /\left[\mathrm{H}^{+}\right]}=\mathscr{D} .
$$

The fraction $V_{a} / V_{b}$ can be expressed as the dilution factor $\mathscr{D}$. The $\mathrm{pH}$ of the resultant solution is defined in terms of the $\mathrm{H}^{+}$concentration

$$
\mathrm{pH}=-\log _{10}\left[\mathrm{H}^{+}\right] \text {. }
$$


At neutralization $\left[\mathrm{H}^{+}\right]=\left[\mathrm{OH}^{-}\right]$and from (2.4), the hydrogen ion concentration is equal to $\left[\mathrm{H}^{+}\right]=K_{w}^{1 / 2}$, giving the dilution required for neutralization as

$$
\mathscr{D}=\frac{C_{a}^{0}}{C_{b}^{0}}\left(\frac{K_{w}^{1 / 2}}{K_{b}}+1\right) \text {. }
$$

The two limits to consider are a strong acid-strong alkali and a strong acid-weak alkali reaction. A strong alkali is characterized by $K_{b} / K_{w}^{1 / 2} \gg 1$, and in this limit the hydrogen ion concentration is calculated from the quadratic

$$
\left[\mathrm{H}^{+}\right]^{2}(1+\mathscr{D})-\left(C_{a}^{0}-\mathscr{D} C_{b}^{0}\right)\left[\mathrm{H}^{+}\right]-(1+\mathscr{D}) K_{w}=0 .
$$

The quadratic equation can be solved for $\left[\mathrm{H}^{+}\right]$giving

$$
\left[\mathrm{H}^{+}\right]=\frac{1}{2}\left(\frac{C_{a}^{0}-\mathscr{D} C_{b}^{0}}{1+\mathscr{D}} \pm \sqrt{\left(\frac{C_{a}^{0}-\mathscr{D} C_{b}^{0}}{1+\mathscr{D}}\right)^{2}+4 K_{w}}\right) .
$$

When the reaction is far from neutralization and acidic (i.e. $\left(C_{a}^{0}-\mathscr{D} C_{b}^{0}\right) /(1+\mathscr{D}) \gg$ $K_{w}^{1 / 2}$ ), the hydrogen ion concentration is

$$
\left[\mathrm{H}^{+}\right] \simeq \frac{C_{a}^{0}-\mathscr{D} C_{b}^{0}}{1+\mathscr{D}} .
$$

Physically (2.9) shows that $\left[\mathrm{H}^{+}\right]$decreases due to the reaction (i.e. the numerator $\left.C_{a}^{0}-\mathscr{D} C_{b}^{0}\right)$ and the dilution (i.e. the denominator $\left.1 /(1+\mathscr{D})\right)$. Beyond neutralization (i.e. $\mathscr{D} C_{b}^{0}>C_{a}^{0}$ and $\left.\left[\mathrm{H}^{+}\right] \ll K_{w}^{1 / 2}\right)$, the first term in $(2.7)\left(\left[\mathrm{H}^{+}\right]^{2}(\mathscr{D}+1)\right)$ is small compared with the last term and, therefore, equations (2.7) and (2.8) can be reduced to

$$
\left[\mathrm{H}^{+}\right] \simeq \frac{(1+\mathscr{D}) K_{w}}{\mathscr{D} C_{b}^{0}-C_{a}^{0}}
$$

For a weak alkali, characterized by $K_{w} /\left[\mathrm{H}^{+}\right] \gg K_{b}$, the balance in (2.4) reduces to

$$
\left[\mathrm{H}^{+}\right]^{2}\left(1+\mathscr{D}+C_{b}^{0} \mathscr{D} K_{b} / K_{w}\right)-C_{a}^{0}\left[\mathrm{H}^{+}\right]-(1+\mathscr{D}) K_{w}=0 .
$$

Figure 1 shows the $\mathrm{pH}$ variation of a mixture formed by titrating a strong acid against a alkali at $25^{\circ} \mathrm{C}$. Figure $1(a)$ shows the case of a strong acid-strong alkali reaction for varying concentration of the alkali, where the concentration of acid is the same in each curve. The comparison between (2.9) (for $\mathrm{pH}<7$ ) and (2.10) (for $\mathrm{pH}>7$ ) is good and finally asymptotes to $\mathrm{pH}=-\log _{10}\left(K_{w} / C_{b}^{0}\right)=14+\log _{10} C_{b}^{0}$. We see that close to neutralization the $\mathrm{pH}$ varies rapidly with $\mathscr{D}$. Figure $1(b)$ shows the strong acid-weak alkali reaction, the dashed lines correspond to (2.8) for $\mathrm{pH}<5$ and (2.11) for $\mathrm{pH}>5$.

\subsection{Fluid-flow model}

A standard approach for modelling a turbulent plume is to consider how the mean flow velocity $w$, radius $b$ and density contrast between the plume $\rho$ and ambient $\rho_{a}$ vary with distance $z$ from the source. We apply the assumption of Morton et al. (1956, page 5, (2)) that the profiles are top-hat which is consistent with the recent work by Westerweel and others (Westerweel et al. 2005; Hunt et al. 2006; Westerweel et al. 2009) in which the conditionally averaged properties (velocity and concentration) (Bisset, Hunt \& Rogers 2002) exhibit a large jump at the interface between the turbulent and non-turbulent regions. Averaging measurements over time provides velocity and concentration profiles which appear to be close to Gaussian in 

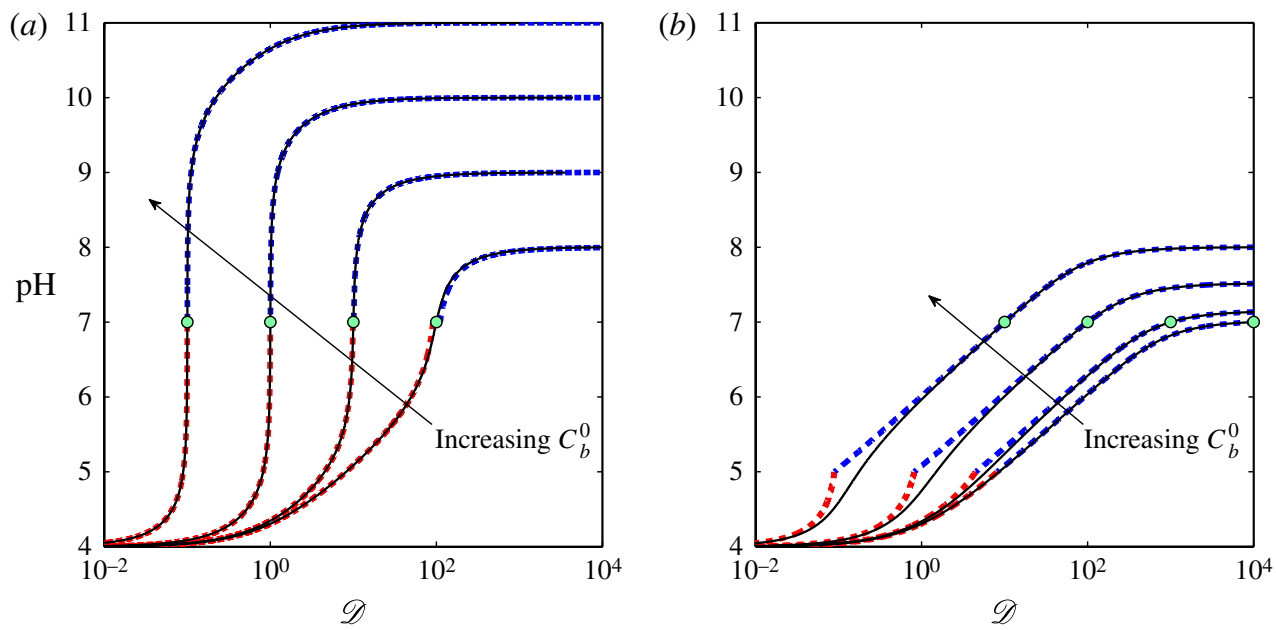

FIGURE 1. Theoretical titration curves for $(a)$ strong acid-strong alkali reaction $\left(K_{b}=\right.$ $\left.10^{1} \mathrm{~mol}^{-1}\right)$ and $(b)$ strong acid-weak alkali reaction $\left(K_{b}=10^{-9} \mathrm{~mol} \mathrm{l}^{-1}\right)$ at $25^{\circ} \mathrm{C}\left(K_{w}=\right.$ $10^{-14} \mathrm{~mol}^{2} \mathrm{l}^{-2}$ ) are described by a solid line (2.4) in the limit of $\mathscr{D} \rightarrow \infty$. In both cases $C_{a}^{0}=10^{-4} \mathrm{~mol} \mathrm{l}^{-1}$ and $C_{b}^{0}=10^{-6}, 10^{-5}, 10^{-4}, 10^{-3} \mathrm{~mol}^{-1}$. The dashed lines in $(a)$ correspond to (2.9) for $\mathrm{pH}<7$ and (2.10) for $\mathrm{pH}>7$. In $(b)$, they correspond to (2.8) for $\mathrm{pH}<5$ and (2.11) for $\mathrm{pH}>5$. Points of neutralization are displayed as circles.

form, largely as a consequence of the random meandering of the interface between the turbulent plume and non-turbulent ambient. Gaussian profiles have been the basis of many theoretical models as well (e.g. Jirka 2004) and are conceptually similar to the top-hat approach. The starting point is the conservation of momentum and mass (with an empirical closure for entrainment), which for a top-hat profile are given as

$$
\begin{gathered}
\frac{\mathrm{d}}{\mathrm{d} z}\left(\pi b^{2} w\right)=2 \pi \alpha w b, \\
\frac{\mathrm{d}}{\mathrm{d} z}\left(\pi b^{2} w^{2}\right)=\frac{\left(\rho_{a}-\rho\right)}{\rho_{0}} g \pi b^{2}, \\
\frac{\mathrm{d}}{\mathrm{d} z}\left(\pi b^{2} w g \frac{\left(\rho_{a}-\rho\right)}{\rho_{0}}\right)=0 .
\end{gathered}
$$

The empirically determined entrainment coefficient $\alpha$ in (2.12) shows some variation between plume and jet experiments. Kaminski, Tait \& Carazzo (2005) suggest that the enhancement of plumes is partly explained by the increase in baroclinically generated turbulence. Morton (1959) suggested that the entrainment rate should be related to the local level of turbulence, rather than to the mean flow. Turner (1969) noted that the resulting similarity solutions are not sensitive to the value of $\alpha$, therefore, reasonably accurate solutions can be made on the assumption that they are constant. For this reason, we assume $\alpha=0.1$ for jets and plumes, however, in the work of Hunt \& Kaye (2005) it is suggested that this approach slightly underestimates the entrainment rate in the plume. The system of equations can be re-expressed in terms of specific fluid momentum $\left(M=\pi b^{2} w^{2}\right)$, volume flux $\left(Q=\pi b^{2} w\right)$ and specific buoyancy flux $\left(B=\pi b^{2} w g\left(\rho_{a}-\rho\right) / \rho_{0}\right)$ as

$$
\frac{\mathrm{d} Q}{\mathrm{~d} z}=2 \alpha \pi^{1 / 2} M^{1 / 2}, \quad \frac{\mathrm{d} M}{\mathrm{~d} z}=\frac{B Q}{M}, \quad \frac{\mathrm{d} B}{\mathrm{~d} z}=0 .
$$


Using the dimensionless variables, $\tilde{Q}=Q / Q_{0}, \quad \tilde{M}=M / M_{0}, \quad \tilde{B}=B / B_{0}=1$ and $\tilde{z}=2 \alpha z / b_{0}$, the characteristics of the plume can be expressed as

$$
\frac{\mathrm{d} \tilde{Q}}{\mathrm{~d} \tilde{z}}=\tilde{M}^{1 / 2}, \quad \frac{\mathrm{d} \tilde{M}}{\mathrm{~d} \tilde{z}}=\frac{4}{5} \Gamma_{0} \frac{\tilde{Q}}{\tilde{M}},
$$

where

$$
\Gamma_{0}=\frac{5 B_{0} Q_{0}^{2}}{8 \alpha \pi^{1 / 2} M_{0}^{5 / 2}} .
$$

Here $\Gamma_{0}$ is a dimensionless measure of the relative strength of the initial buoyancy flux of the plume and can be used to classify the nature of the source, i.e. for jets $\Gamma_{0}=0$, forced plumes $0<\Gamma_{0}<1$, pure plumes $\Gamma_{0}=1$ and lazy plumes $\Gamma_{0}>1$ (Hunt \& Kaye 2001, 2005).

The system in $(2.16 a, b)$ can be solved using the relationship

$$
\tilde{M}=\left(1+\Gamma_{0}\left(\tilde{Q}^{2}-1\right)\right)^{2 / 5},
$$

between $\tilde{M}$ and $\tilde{Q}$. The volume flux $\tilde{Q}$ can be expressed implicitly in terms of the distance $\tilde{z}$ from the source through

$$
\tilde{z}=\int_{1}^{\tilde{Q}} \frac{\mathrm{d} \tilde{Q}}{\left(\Gamma_{0}\left(\tilde{Q}^{2}-1\right)+1\right)^{1 / 5}} .
$$

For a pure jet source $\left(\Gamma_{0}=0\right)$, the radius and volume flux increase linearly with distance

$$
b=b_{0}+2 \alpha z, \quad \tilde{Q}=1+\tilde{z} .
$$

For $\Gamma_{0}>0$, the asymptotic form can be obtained by writing (2.19), in the limit of $\tilde{Q} \rightarrow \infty$ asymptotic spread in the far field, accounting for the virtual origin $\tilde{z}$

$$
b=b_{0}+\frac{6}{5} \alpha z, \quad \tilde{Q} \sim\left(\frac{3}{5}\left(\tilde{z}-\tilde{z}_{0}\right)\right)^{5 / 3} \Gamma_{0}^{1 / 3},
$$

where the virtual origin is

$$
\tilde{z}_{0}=-\frac{1}{\Gamma_{0}^{1 / 5}} \int_{1}^{\infty}\left(\frac{1}{\left(\tilde{Q}^{2}-1+\Gamma_{0}^{-1}\right)^{1 / 5}}-\frac{1}{\tilde{Q}^{2 / 5}}\right) \mathrm{d} \tilde{Q}-\frac{5}{3} \Gamma_{0}^{1 / 5} .
$$

When $\Gamma_{0}=1$ and $\tilde{z}_{0}=5 / 3$, equations $(2.21 a, b)$ reduce to

$$
b=b_{0}+\frac{6}{5} \alpha z, \quad \tilde{Q}=\left(\frac{3 \tilde{z}}{5}+1\right)^{5 / 3} .
$$

Figure 2(a) shows the variation of $\tilde{Q}$ with $\tilde{z}$ for a range of $\Gamma_{0}$ values. For $\left|\Gamma_{0}-1\right| /\left(\tilde{Q}^{2} \Gamma_{0}\right) \ll 1$, the virtual origin can be approximated as

$$
\tilde{z}_{0} \sim-\frac{32}{21 \Gamma_{0}^{1 / 5}}-\frac{1}{7 \Gamma_{0}^{6 / 5}} .
$$

Figure 2(b) shows the variation of the virtual origin with $\Gamma_{0}$ and it can be concluded that (2.24) is a reasonable approximation for $\Gamma_{0}>0.2$. 

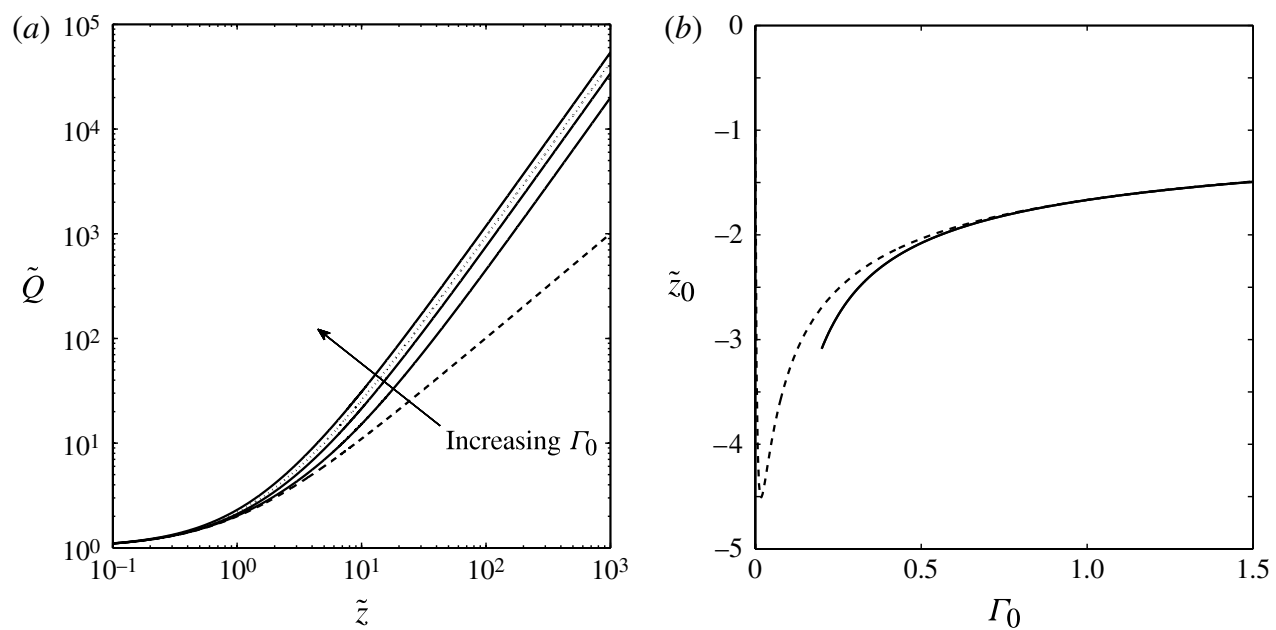

FIGURE 2. In $(a)$ the numerical volume flux against distance for a range of $\Gamma_{0}=0$ (dashed line), $0.1,0.5,1$ (dotted line) and 2 . In (b) the variation of the virtual origin $\tilde{z}_{0}$ as a function $\Gamma_{0}$ (2.22) (dashed line) compared against the analytical approximation (2.24) (solid line).

The travel time of the fluid which is either formed as a part of the initial discharge or is entrained by the jet or plume from the point of origin to a distance $z$ is defined as

$$
t(z)=\int_{0}^{z} \frac{\mathrm{d} z}{w}
$$

Equation (2.25) is evaluated in a dimensionless form, $\tilde{t}=2 \alpha w_{0} t / b_{0}$, where

$$
\tilde{t}=\int_{1}^{\tilde{Q}} \frac{\tilde{Q}}{\tilde{M}} \mathrm{~d} \tilde{z}=\int_{1}^{\tilde{Q}} \frac{\tilde{Q} \mathrm{~d} \tilde{Q}}{\left(1+\Gamma_{0}\left(\tilde{Q}^{2}-1\right)\right)^{3 / 5}}
$$

Again, there are two limiting cases of a pure jet $\left(\Gamma_{0}=0\right)$

$$
\tilde{t}=\frac{1}{2} \tilde{z}^{2}+\tilde{z}
$$

and for a plume $\left(\Gamma_{0}>0\right)$

$$
\tilde{t} \sim \frac{5}{4}\left(\frac{5 \tilde{z}}{3}\right)^{4 / 3} \Gamma_{0}^{-1 / 3}
$$

Figure 3 shows the variation of travel time with distance and volume flux. The velocity in the jet decays as $w \sim z^{-2}$ and in the plume as $w \sim z^{-1 / 3}$. Owing to the different rates of velocity decay the travel time increases much more rapidly with distance from the nozzle for a jet than for a plume.

\subsection{Combined chemistry and fluid-flow model}

The concentration of acid in a jet or plume decreases with distance from the point of origin through the combination of dilution and chemical reactions. The mass conservation equations for the jet and plume are

$$
\begin{aligned}
\frac{\mathrm{d}}{\mathrm{d} z}\left(\pi b^{2} w\left[\mathrm{~A}^{-}\right]\right) & =0, \\
\frac{\mathrm{d}}{\mathrm{d} z}\left(\pi b^{2} w\left([\mathrm{MOH}]+\left[\mathrm{M}^{+}\right]\right)\right) & =2 \alpha \pi b w C_{b}^{0} .
\end{aligned}
$$




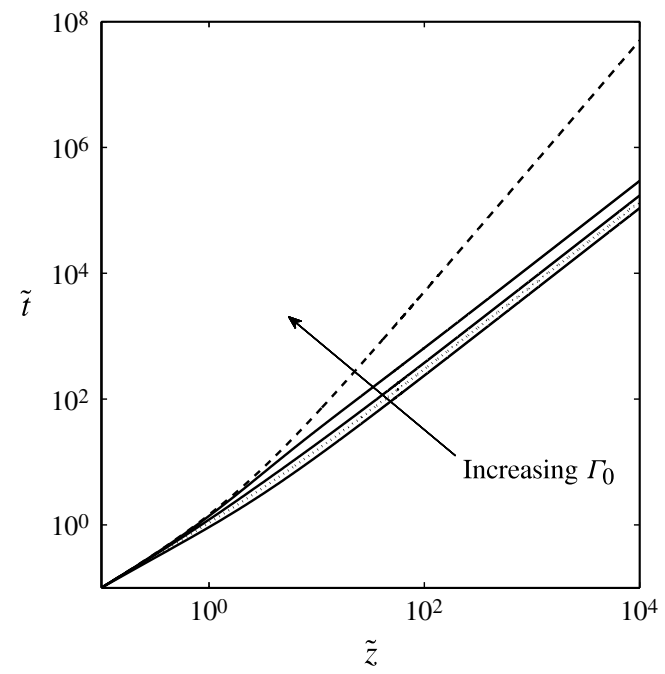

FIGURE 3. The numerical travel time against distance where $\Gamma_{0}=0$ (dashed line), $0.1,0.5,1$ (dotted line) and 2.

The amount of acid within the jet or plume is described by (2.29) while (2.30) describes the increase in the alkali component within the jet or plume due to entrainment. The initial conditions at $\tilde{z}=0$ are

$$
\left[\mathrm{A}^{-}\right]=C_{a}^{0}, \quad[\mathrm{MOH}]+\left[\mathrm{M}^{+}\right]=0 .
$$

The concentration of acid decreases due to dilution, where

$$
\tilde{Q}=1+\mathscr{D} \text {. }
$$

The solutions to (2.29) and (2.30) can be expressed in terms of volume flux as this determines the dilution of the acid and the increase in concentration of the alkali within the jet or plume, i.e.

$$
\left[\mathrm{A}^{-}\right]=\frac{C_{a}^{0}}{\tilde{Q}}, \quad[\mathrm{MOH}]+\left[\mathrm{M}^{+}\right]=\frac{C_{b}^{0}(\tilde{Q}-1)}{\tilde{Q}} .
$$

The terms in $(2.33 a, b)$ are rearranged from $(2.2 a, b)$ and are strictly valid for when the anion $\mathrm{A}^{-}$is not present in the ambient and the alkali in the ambient has a uniform concentration of $\mathrm{MOH}$. The condition for neutralization is stated in (2.6). The expressions for neutralization of a jet $\left(\Gamma_{0}=0\right)$ can be obtained by combining $(2.20 b)$, (2.32) and (2.6) resulting in

$$
\tilde{z}_{N}=\frac{C_{a}^{0}}{C_{b}^{0}}\left(\frac{K_{w}^{1 / 2}}{K_{b}}+1\right) .
$$

In the case of a plume $\left(\Gamma_{0}>0\right)$, combining (2.21b), (2.32) and (2.6) results in

$$
\tilde{z}_{N}=\frac{5}{3 \Gamma_{0}^{1 / 5}}\left[1+\frac{C_{a}^{0}}{C_{b}^{0}}\left(\frac{K_{w}^{1 / 2}}{K_{b}}+1\right)\right]^{3 / 5}+\tilde{z}_{0} .
$$

Figure $4(a, b)$ shows the $\mathrm{pH}$ along the centreline in the jet and plume as a function of distance from the source, for the case of a strong acid injected into a strong alkali. 


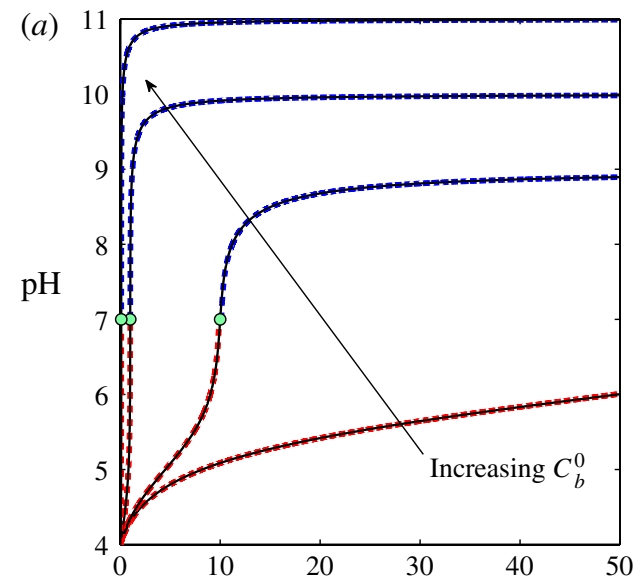

(b)
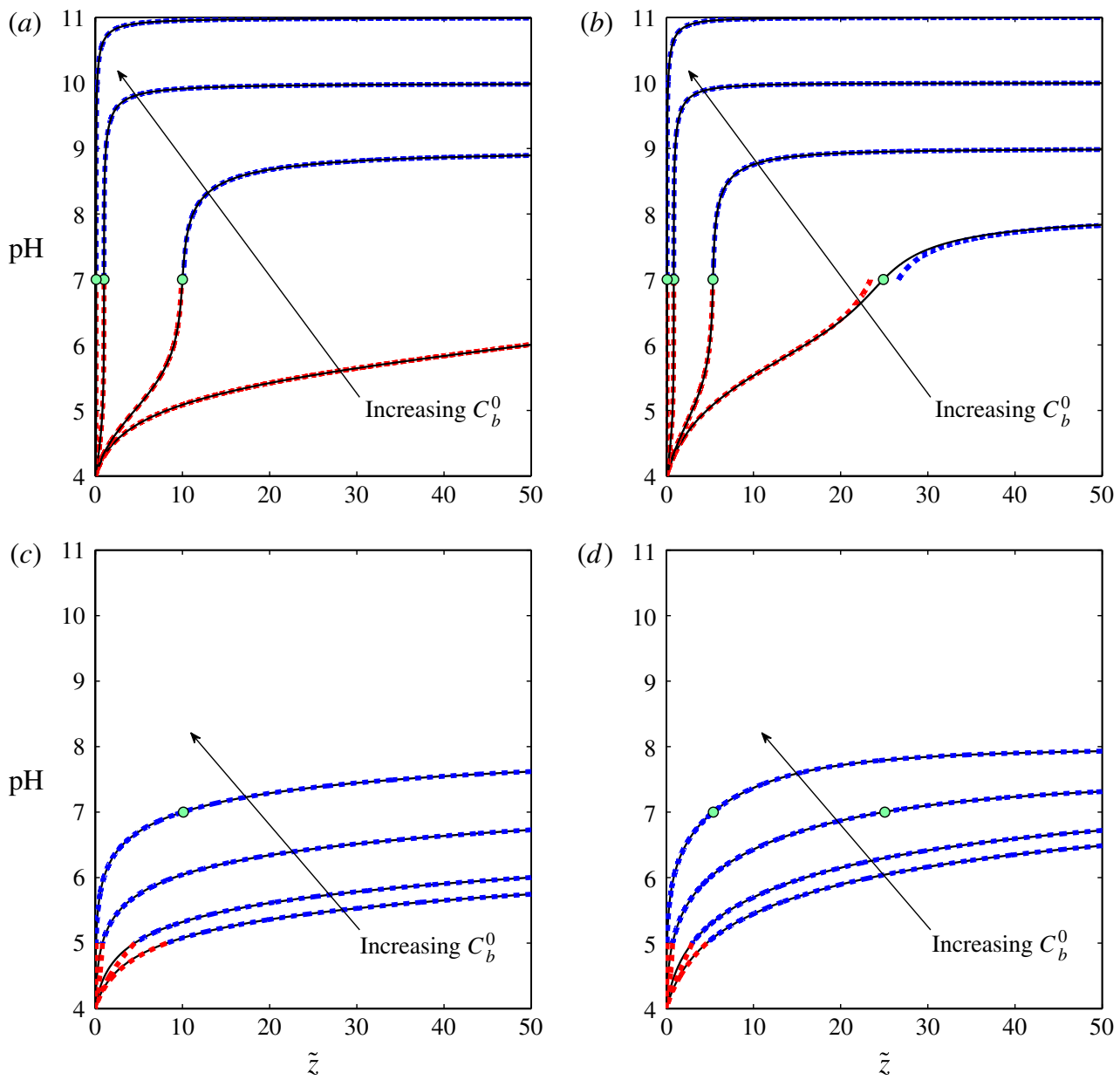

FIgURE 4. The $\mathrm{pH}$ of an acidic $C_{a}^{0}=10^{-4}$ jet $(a, c)$ and plume $(b, d)$ is plotted for four cases of initial ambient alkaline concentration $C_{b}^{0}=10^{-6}, 10^{-5}, 10^{-4}, 10^{-3} \mathrm{~mol}^{-1}$ : (a) $\Gamma_{0}=0$; (b) $\Gamma_{0}=1 ;(c) \Gamma_{0}=0 ;(d) \Gamma_{0}=1$. In $(a, b)$ the alkaline ambient is strong $\left(K_{b}=1 \mathrm{~mol} \mathrm{l}^{-1}\right)$ and in $(c, d)$ the alkaline ambient is weak $\left(K_{b}=10^{-9} \mathrm{~mol} \mathrm{l}^{-1}\right)$. The points of neutralization are plotted as circles that are defined by (2.34) in the case of the jet and by (2.35) in the case of a plume. The solid lines correspond to (2.4) where $\mathscr{D}=\tilde{Q}-1$ is expressed as a function of $\tilde{z}$ and the dashed lines are the same as on figure 1.

In the case when the concentrations of acid and alkali are both high the results are insensitive to $\Gamma_{0}$ because the alkali solution is so strong that neutralization occurs close to the source. When the concentration of the alkali is reduced, neutralization occurs further away from the nozzle. As the neutralization distance increases so does the momentum flux in the case of a plume and that has a significant effect on increasing the neutralization distance. The variation of the $\mathrm{pH}$ in the acidic discharge can then be calculated by expressing $\mathscr{D}=\tilde{Q}-1$ as a function of $\tilde{z}$ and substituting this into (2.4) to determine $\left[\mathrm{H}^{+}\right]$. The results for a strong acid injected into a weak alkali are shown in figure $4(c, d)$. Both the weak and strong alkalis increase the acid $\mathrm{pH}$ by the same amount in approximately the same distance, $\tilde{z}$, up until a $\mathrm{pH}$ of 5 . 


\begin{tabular}{|c|c|c|c|c|c|}
\hline Tank additions & $C_{a}^{0}$ & $C_{b}^{0}$ & $\frac{C_{a}^{0}-C_{l}-C_{w}}{C_{b}^{0}+C_{w}}$ & Exp. $\tilde{z}_{N}$ & Theo. \\
\hline \multicolumn{6}{|l|}{ Jets } \\
\hline None & 0.0364 & 0.0000 & 17.90 & 17.90 & 17.90 \\
\hline $\mathrm{NaOH}$ (aq.) & 0.0364 & 0.0002 & 16.57 & 15.75 & 16.57 \\
\hline $\mathrm{NaOH}$ (aq.) & 0.0364 & 0.0005 & 14.43 & 14.73 & 14.43 \\
\hline $\mathrm{NaOH}$ (aq.) & 0.0364 & 0.0008 & 12.78 & 14.29 & 12.78 \\
\hline $\mathrm{NaOH}$ (aq.) & 0.0364 & 0.0011 & 11.48 & 10.86 & 11.48 \\
\hline Buffer $(50 \%)$ & 0.0364 & 0.0006 & 13.54 & 11.43 & 13.54 \\
\hline Buffer (100\%) & 0.0364 & 0.0012 & 10.88 & 9.14 & 10.88 \\
\hline Buffer $(150 \%)$ & 0.0364 & 0.0019 & 9.10 & 9.40 & 9.10 \\
\hline Buffer $(200 \%)$ & 0.0348 & 0.0025 & 7.47 & 7.75 & 7.47 \\
\hline Buffer $(250 \%)$ & 0.0348 & 0.0031 & 6.55 & 8.06 & 6.55 \\
\hline Buffer $(300 \%)$ & 0.0348 & 0.0037 & 5.83 & 6.22 & 5.83 \\
\hline $\mathrm{NaOH}$ (salt) & 0.0348 & 0.0008 & 12.11 & 14.03 & 12.11 \\
\hline $\mathrm{NaOH}$ (salt) & 0.0348 & 0.0011 & 10.94 & 11.49 & 10.94 \\
\hline $\mathrm{NaOH}$ (salt) & 0.0348 & 0.0013 & 10.09 & 11.49 & 10.09 \\
\hline $\mathrm{NaOH}$ (salt) & 0.0348 & 0.0018 & 8.83 & 9.53 & 8.83 \\
\hline \multicolumn{6}{|l|}{ Plumes } \\
\hline None & 0.0400 & 0.0000 & 19.68 & 7.18 & 7.00 \\
\hline $\mathrm{NaOH}$ (salt) & 0.0400 & 0.0006 & 14.76 & 5.56 & 5.83 \\
\hline $\mathrm{NaOH}$ (salt) & 0.0400 & 0.0013 & 11.95 & 4.91 & 5.10 \\
\hline $\mathrm{NaOH}$ (salt) & 0.0400 & 0.0016 & 10.92 & 4.93 & 4.81 \\
\hline $\mathrm{NaOH}$ (salt) & 0.0400 & 0.0019 & 9.99 & 3.09 & 4.23 \\
\hline $\mathrm{NaOH}$ (salt) & 0.0400 & 0.0025 & 8.58 & 2.09 & 3.84 \\
\hline $\mathrm{NaOH}$ (salt) & 0.0400 & 0.0031 & 7.55 & 3.88 & 3.82 \\
\hline $\mathrm{NaOH}$ (salt) & 0.0400 & 0.0047 & 5.77 & 1.91 & 2.99 \\
\hline $\mathrm{NaOH}$ (salt) & 0.0400 & 0.0063 & 4.64 & 2.15 & 2.83 \\
\hline $\mathrm{HNO}_{3}$ & 0.0400 & -0.0006 & 28.97 & 8.51 & 8.95 \\
\hline $\mathrm{HNO}_{3}$ & 0.0400 & -0.0009 & 37.91 & 10.72 & 10.62 \\
\hline
\end{tabular}

TABLE 1. List of the chemical composition of the jet, plume and tank water. The dimensionless experimental neutralization distance $\tilde{z}_{N}$ is measured from time averaged jet or plume images. The $100 \%$ buffer solution is created from $0.057 \mathrm{~g} \mathrm{l}^{-1}$ of sodium bicarbonate (molar mass $84 \mathrm{~g} \mathrm{~mol}^{-1}$ ) and $0.163 \mathrm{~g} \mathrm{l}^{-1}$ of sodium carbonate decahydrate (molar mass $286 \mathrm{~g} \mathrm{~mol}^{-1}$ ). The molar mass of sodium hydroxide is $40 \mathrm{~g} \mathrm{~mol}^{-1}$. The molarity of London tap water was estimated to be $C_{w}=0.0019 \mathrm{~mol} \mathrm{l}^{-1}$ from the jet experiments and $C_{l}=3.5 \times 10^{-5} \mathrm{~mol} \mathrm{l}^{-1}$ is the alkalinity of the litmus solution.

Far downstream, the $\mathrm{pH}$ of the discharge into a weak alkali solution has a minor dependence on $C_{b}^{0}$ than for the strong alkali case and a much lower $\mathrm{pH}$.

\section{Experimental study}

The purpose of the experimental study is to investigate the effects of the ambient alkaline fluid chemical composition and concentration on the neutralization distances of jets/plumes and to provide a comparison between the predicted points of neutralization and experimental observations. To reduce the number of variables in the experiments acid type (nitric acid), acid concentration and flow rate were fixed in the jet and plume as well as the buoyancy flux in the case of the plume. The jets and plumes were generated by a hydrostatic head of water from a large header tank. Table 1 lists the substances used to increase the alkalinity of the ambient fluid. 
The jet experiments took place in a wide rectangular tank with planform crosssectional dimensions of $1.46 \mathrm{~m} \times 0.97 \mathrm{~m}$, filled to a depth of $0.46 \mathrm{~m}$. The tank was illuminated by diffuse light sources from its bottom and along its side. In the case of the plume, the tank planform cross-sectional dimensions were $0.5 \mathrm{~m} \times 0.5 \mathrm{~m}$, filled to a depth of $0.66 \mathrm{~m}$ and the tank was illuminated by a diffuse light source from one side. The internal radius of the nozzle was fixed at $b_{0}=0.011 \mathrm{~m}$ for the jet and $b_{0}=0.004 \mathrm{~m}$ for the plume. The nozzle design for the plume was similar to the Cooper nozzle that is described by Kaye \& Linden (2004). The flow rate for the jet at the end the nozzle was $Q=1.31 \times 10^{-4} \mathrm{~m}^{3} \mathrm{~s}^{-1}$. A dense plume was created by adding sodium chloride to a vertical discharge which does not play a role in the acid-alkali reactions. For the case of a plume, $Q=2.53 \times 10^{-6} \mathrm{~m}^{3} \mathrm{~s}^{-1}, \Delta \rho_{0}=36.59 \mathrm{~kg} \mathrm{~m}^{-3}$ resulting in $\Gamma_{0}=3.55$ at the end of the nozzle. The characteristic Reynolds number $\left(R e=2 b_{0} w_{0} / \nu\right)$ for the jet is $R e=7551$ and for the plume is $R e=399$.

The neutralization distances of the jets and plumes were determined optically from the litmus dye in the discharge. The significant quantities of water involved in these experiments precluded the use of distilled or deionized water, consequently, central London tap water at a temperature of $19{ }^{\circ} \mathrm{C}$ was used in all of the experiments. In the absence of any additional basic salts the jet neutralization distance was used to infer the concentration of dissolved salts in the tank $\left(C_{w}^{0}=0.0019 \mathrm{~mol} \mathrm{l}^{-1}\right)$. The chemical characteristics of the tank water were changed by the addition of a buffer salt combination, a single salt, an alkaline solution or an acidic solution. By adding alkali salts, the water became increasingly opaque to the point where the presence of the indicator could no longer be detected in the tank. This limited the shortest neutralization distance that could be observed. When additional basic salts were added, the total basic molar concentration in the tank was estimated to be the sum of $C_{b}^{0}$ and $C_{w}$, the molar concentration of the added alkalis and tap water.

All the experiments were recorded with a colour camera (Sony HDR-SR12E) at a resolution of $1920 \times 1080$ pixels, 24-bit colour depth and 25 frames per second. The videos were converted into a sequence of images at the video frame rate. A number of routines were written in Matlab R2012a using the image processing toolbox to gain either an instantaneous view of the colour intensity fields or a time averaged measure. The averaged images were created over a time period of $7 \mathrm{~s}$. The images were split into red, green and blue colour components to gain a quantitative overview of how the colour intensity along the jet and plume centreline changed with distance from the nozzle. In the RGB colour model the colour intensity is within the range of 0 to 255 for each colour. The maximum colour intensity varies greatly depending on the opacity of the water in the tank, however, the relationship between the different colour components remains the same as distance from the nozzle increases.

Titration experiments were undertaken to examine how the $\mathrm{pH}$ and colour of the indicator dyes changed as acid reacted with an alkaline fluid. A diluted acid solution was created from a $1 \mathrm{~N}$ standard nitric acid solution (Fluka Analytical) in distilled water and titrated against a sodium hydroxide solution in distilled water. The titration experiments involved increasing the volume of an initially acidic solution with an alkaline solution that was then stirred for a short period of time. The $\mathrm{pH}$ was measured using the Hannah Instruments HI 8428NEW probe two minutes after stirring. Litmus and universal indicator dyes were also used to determine the $\mathrm{pH}$ from the colour of the solution. The reaction occurred in a Pyrex beaker, placed on top of a small diffuse light box. 


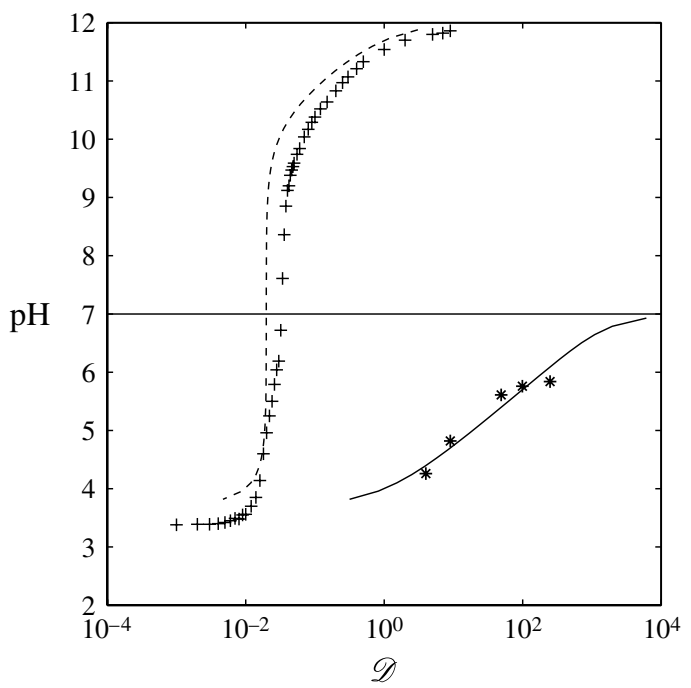

FIGURE 5. The $\mathrm{pH}$ titration curves of nitric acid $\left(C_{a}^{0}=0.0002 \mathrm{~mol}^{-1}\right)$ being titrated against a sodium hydroxide solution $C_{b}^{0}=0.01 \mathrm{~mol}^{-1}$ (dashed line) and distilled water $C_{b}^{0}=0 \mathrm{~mol}^{-1}$ (solid line). The solid and dashed lines show the theoretical predictions (2.4) while the symbols correspond to experimental data.

\section{Experimental results}

\subsection{Titration experiments}

Figure 5 shows the variation $\mathrm{pH}$ in a nitric acid solution as it is diluted with concentrated sodium hydroxide solution. The titration curve shows that when $C_{b}^{0}$ is large, the $\mathrm{pH}$ changes rapidly through the point of neutralization. As discussed in $\S 3 \mathrm{pH}$ titration curves are affected by both chemical reactions and dilution. The titration of acid against distilled water $\left(C_{b}^{0}=0 \mathrm{~mol} \mathrm{l}^{-1}\right)$ shows a change in the $\mathrm{pH}$ occurring wholly due to dilution. The $\mathrm{pH}$ in this case was measured with a $\mathrm{pH}$ probe. It is worth noting that the experiments involving distilled water are very sensitive to contamination.

Figure 6 shows how the colour of the litmus dye changes due to nitric acid being titrated against sodium hydroxide. As the amount of alkali added increases, the $\mathrm{pH}$ quickly passes through the point of neutralization and a corresponding rapid change in colour from red to blue is observed. Based on the colour intensity difference we are able to identify the point of neutralization.

\subsection{Dilution and neutralization}

The mixing in the jet was examined using litmus dye without the addition of acid and the results are shown in figure 7. The instantaneous image (figure 7a) shows a sharp jet edge, but averaging over time (figure $7 b$ ), generates a smooth interface. The entrainment of packets of fluid from the edges of the jet or plume to the centre is characterized by a turbulent diffusivity which scales as $\mathscr{D} \sim \lambda w b \sim \lambda M^{1 / 2}$, where $\lambda \sim 0.1$ (Prandtl 1954). The turbulent diffusivity remains constant for a jet while in the case of a plume it increases due to growth in $M$. This means that the mixing at a fixed distance $z$ from the nozzle is not instantaneous and explains why the edges are neutralized first and the centreline last. The distance between the concentration variation from the nozzle to point $z$ along centre of the jet and from the nozzle to 


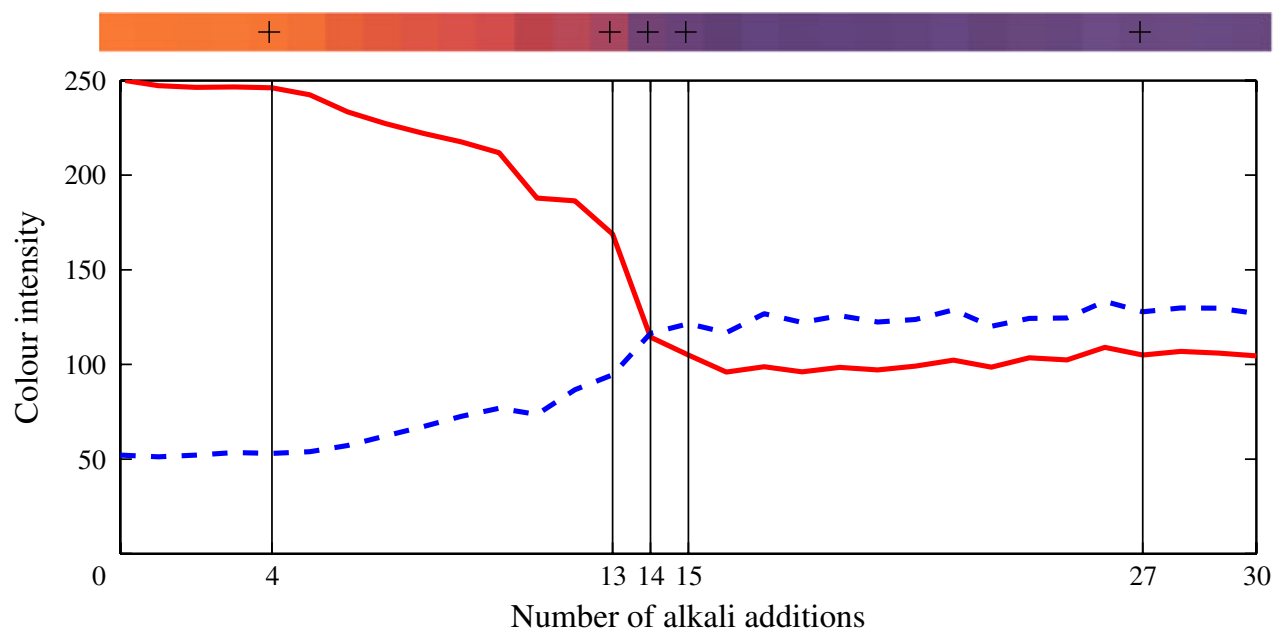

FIGURE 6. Experimental results from the titration experiments of nitric acid and sodium hydroxide in distilled water. The initial volume $(200 \mathrm{ml})$ and alkalinity $\left(C_{a}^{0}=0.0014 \mathrm{~mol}^{-1}\right)$ of the acidified solution increases through the addition of a fixed volume $(2 \mathrm{ml})$ of alkali $\left(C_{b}^{0}=0.01 \mathrm{~mol} \mathrm{l}^{-1}\right)$ at every step for 30 steps. The colour component intensity (dashed line, blue component; solid line, red component) of the $\mathrm{pH}$-sensitive dye, litmus, varies and is highlighted at the following steps: step $4, \mathrm{pH} \approx 3$; step $13, \mathrm{pH} \approx 4$; step $14, \mathrm{pH} \approx 7$; step 15 , $\mathrm{pH} \approx 10$; step $27, \mathrm{pH} \approx 11$.

(a)

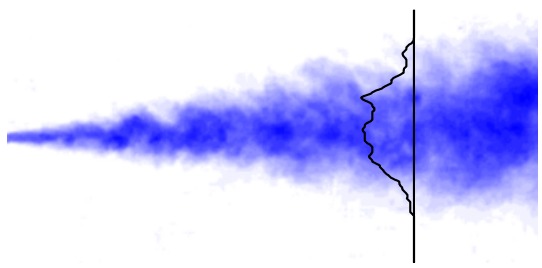

(b)

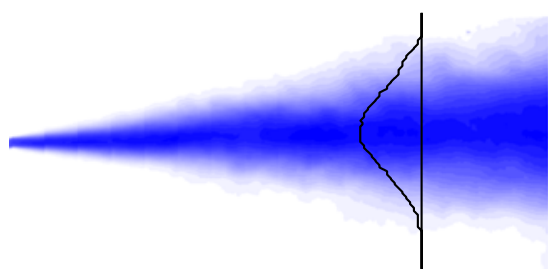

FIGURE 7. The blue colour component intensity for a jet experiment with litmus dye and no acid-alkali neutralization reactions, where $(a)$ is the instantaneous image and $(b)$ is the time-averaged image. The colour component intensity across the jet has been plotted along the vertical straight line.

point $z$ along the edge of the jet scales as $\mathscr{D} / w \sim \lambda b$. This is a fraction of the local width of a turbulent jet or plume. The molecular diffusivity of the chemical species is typically very small $\left(\mathscr{D}_{\text {mol }} \sim 10^{-9} \mathrm{~m}^{2} \mathrm{~s}^{-1}\right)$. The concentration filaments are of the scale $\left(\mathscr{D}_{\text {mol }} L / u^{\prime}\right)^{1 / 2}$ where $L$ is the integral scale and $u^{\prime}$ the root mean square velocity, which has a weak dependence on $\mathscr{D}_{\text {mol }}$ (da Silva et al. 2014).

An instantaneous image of an acidic jet is shown in figure $8(a)$ and quantitative view where the change from red (acidic) to blue (alkaline) occurs in a time averaged jet is show in figure $8(b, c)$. With distance from the nozzle the jet fluid becomes increasingly alkaline due to dilution and chemical reactions. Mixing between the ambient fluid and the jet or plume first occurs on the edges of the discharge where a gradual neutralization gradient is formed towards the centreline. The intensity of the blue and red colour components along the jet centreline are shown in figure 9. The cross-over point corresponds to the point of neutralization, distance $z_{N}$ from the nozzle, 
(a)

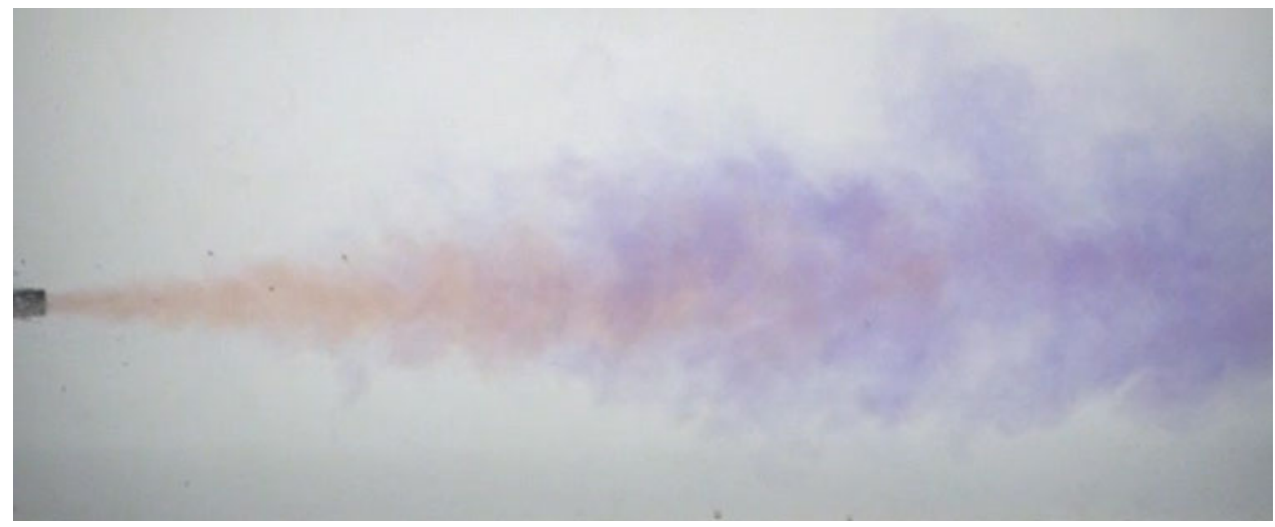

(b)

(c)

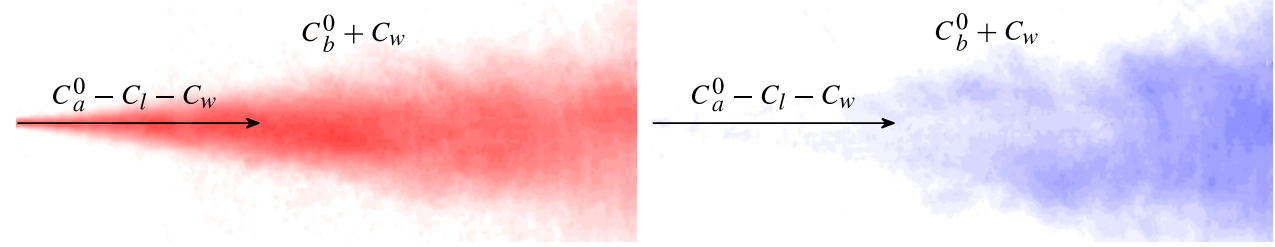

FIGURE 8. An instantaneous image of an acidic turbulent jet $(a)$. A time-averaged jet has been decomposed into $(b)$ red and $(c)$ blue colour components. The jet contains litmus indicator that changes from red to blue as the acidic jet is gradually neutralized.

but in the case that the lines cross multiple times, as seen in figure $9(b)$, the first point of contact is used. With increasing concentration of alkali salts in the ambient, the neutralization distance $z_{N}$ is reduced. It is necessary to take into account the influence of the dissolved salts in the London tap water. In the absence of any additional alkali salts added to the London tap water, the neutralization distance was measured to be $\tilde{z}_{N}=17.9$ in a jet, resulting in an alkali concentration of $C_{w}=0.0019 \mathrm{~mol} \mathrm{l}^{-1}$. The effective concentration of basic salts in the tank is estimated to be $C_{w}+C_{b}^{0}$. The alkalinity of the litmus dye in the discharge is denoted by $C_{l}=3.5 \times 10^{-5} \mathrm{~mol} \mathrm{l}^{-1}$. The total molarity of the acid in the jet and plume is given by $C_{a}^{0}-C_{w}-C_{l}$. The resulting molarity values were substituted into (2.34) for a jet and (2.35) for a plume to obtain theoretical predictions. Figure 10 show a comparison between the experimentally determined neutralization distance and theoretical predictions for jets and plumes respectively.

\section{Practical estimates for acidic discharges into the environment}

We apply the model to examine the $\mathrm{pH}$ of a buoyant vertical discharge into a river or sea. The chemistry of a strong acid reacting with seawater is more complex than the alkaline solution used in the experimental study due to a wide variety of dissolved salts in seawater. To closely mimic the typical reaction between an acid and seawater, we titrated a sample from the River Thames (taken a week before the Olympics at Embankment on Saturday 21 July 2012 at 14:00) and from Brighton Marina (taken on Saturday 22 September 2012 at 14:00). Both samples were taken on days where there was no rain. 


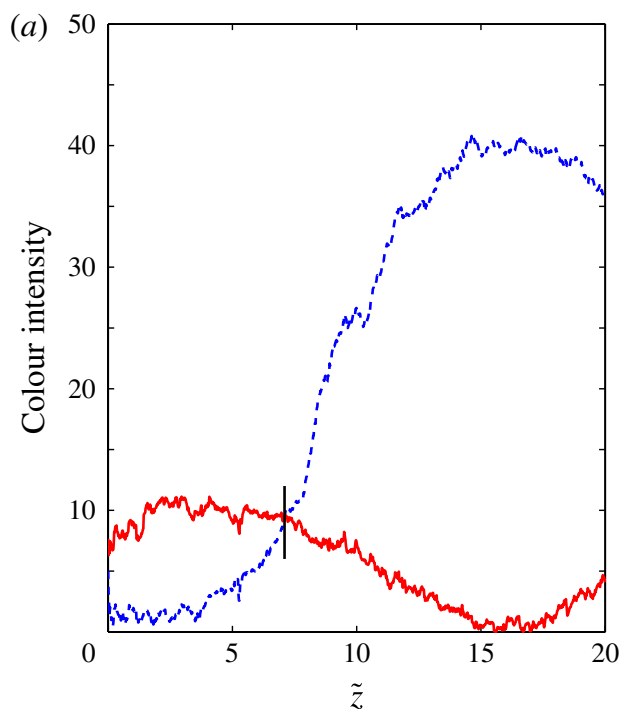

(b)

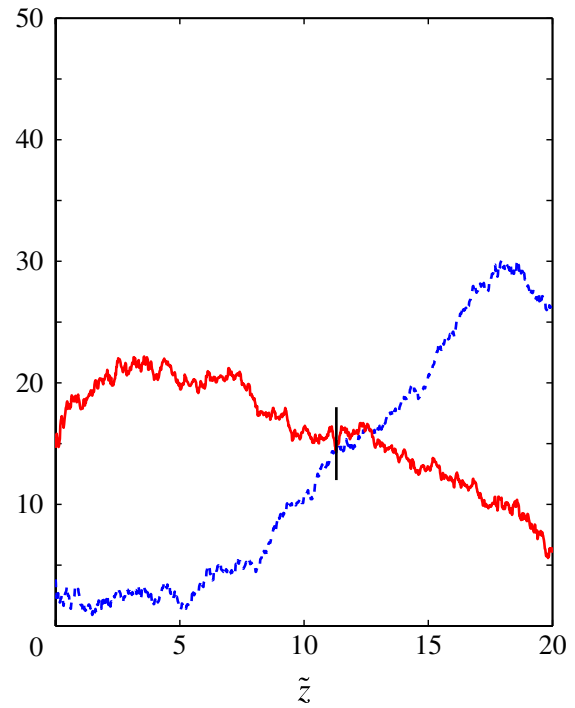

FIGURE 9. The time-averaged intensity of the centreline red (solid line) and blue (dashed line) colour components of a turbulent acidic jet visualized with litmus dye are shown as a function of $\tilde{z}$. Neutralization occurs when the blue colour component intensity becomes equal to the red colour component intensity.

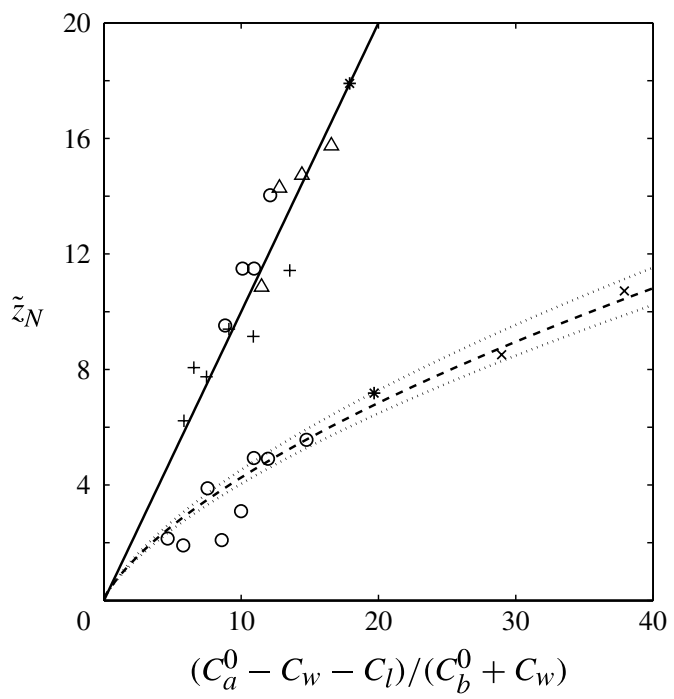

FIGURE 10. The experimental results from table 1 where the $(*)$ symbols are for London tap water, $(\Delta)$ are for sodium hydroxide solution, $(+)$ for buffer solution, $(\bigcirc)$ for sodium hydroxide salt and $(\times)$ for nitric acid. The solid $\left(\Gamma_{0}=0\right)$ and dashed $\left(\Gamma_{0}=3.55\right)$ curves correspond to (2.34) and (2.35), respectively, while the dotted curves give an estimation of error in measuring the plume flow rate.

The Thames is a tidal river; however, at the point and time the sample was taken, the water was essentially fresh with suspended clay sediments. In the past, River Thames water has been used by the scrubber of the Battersea Power Station from 1925 to the 1960 s where the discharge was supplemented with the addition 


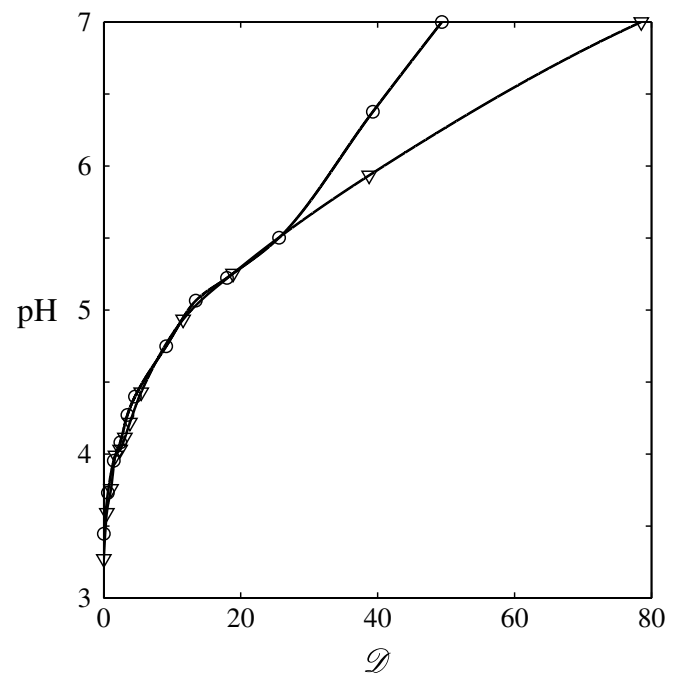

FIGURE 11. Samples of River Thames $(\nabla)$ and Brighton Marina water $(\bigcirc)$ initially acidified with the addition of nitric acid, they were then diluted through the addition of unacidified River Thames/Brighton Marina water. A piecewise cubic spline is fitted to the data.

of alkali agents. Figure 11 shows the variation of $\mathrm{pH}$ in acidified samples of River Thames water and Brighton Marina water as they are diluted through the addition of unacidified River Thames/Brighton Marina water. Samples of $100 \mathrm{ml}$ of river/seawater were acidified with $4 \mathrm{ml}$ of $1 \mathrm{~mol}^{-1}$ nitric acid resulting in $\mathrm{pH}=3.27$ for Thames water and $\mathrm{pH}=3.45$ for Brighton Marina water. The $\mathrm{pH}$ at each stage of the dilution was determined by titrating a $10 \mathrm{ml}$ sample against a sodium hydroxide solution $C_{b}=0.0233 \mathrm{~mol} \mathrm{l}^{-1}$ in the River Thames case and $C_{b}=0.0210 \mathrm{~mol} \mathrm{l}^{-1}$ in the Brighton Marina case. Litmus dye was used to determine the point of neutralization.

The main practical questions are, what key variables control the neutralization distance and by how much should the wash-water be diluted prior to injection into the ambient water? The subtle aspect is that dilution raises the initial $\mathrm{pH}$ but decreases the initial buoyancy flux of the discharge due to a reduction in temperature resulting in reduced entrainment by the plume. The density contrast between the discharge and the ambient can be estimated in terms of the temperature difference $\Delta T$

$$
\rho_{0}-\rho_{a 0}=\gamma \Delta T,
$$

where $\gamma$ is the thermal expansion coefficient of water that varies with temperature. The discharge characteristics are assumed to be $\mathrm{pH}=3.27$ and $T=40{ }^{\circ} \mathrm{C}(\gamma=$ $\left.3.84 \times 10^{-4} \mathrm{~kg} \mathrm{~m}^{-3}{ }^{\circ} \mathrm{C}^{-1}\right)$. The ambient is assumed to have a temperature of $10{ }^{\circ} \mathrm{C}\left(\gamma=0.88 \times 10^{-4} \mathrm{~kg} \mathrm{~m}^{-3}{ }^{\circ} \mathrm{C}^{-1}\right)$ and the relationship between $\mathrm{pH}$ and dilution featured in figure 11 . We are interested in an unstratified environment where the plume is characterized by

$$
\Gamma_{0}=\frac{5 \Delta \rho g \pi^{2} b_{0}^{5}}{8 \alpha \rho_{0} Q_{0}^{2}},
$$

which is expressed in terms of parameters that would be part of any design procedure such as the discharge pipe radius $b_{0}$ and volume flux $Q_{0}$. The scrubber volume flux (quantity of water used to spray the exhaust gas) is proportional to the rate at which fuel is consumed in the engine and the fuel sulphur molarity. The volume flux of 
(a)

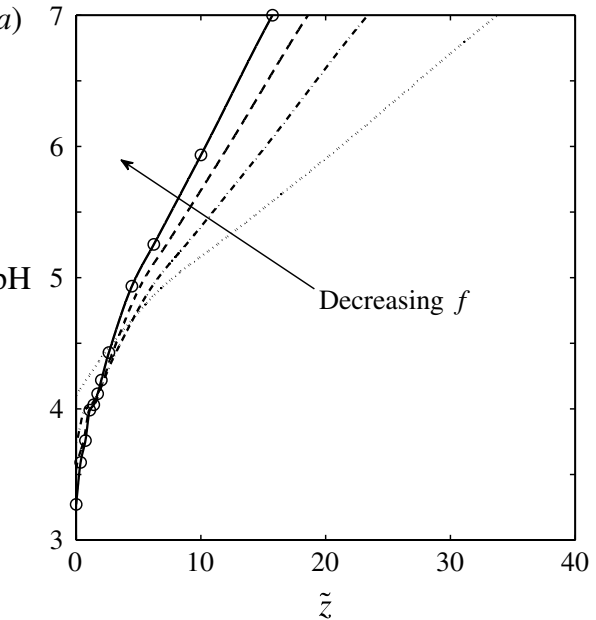

(b)

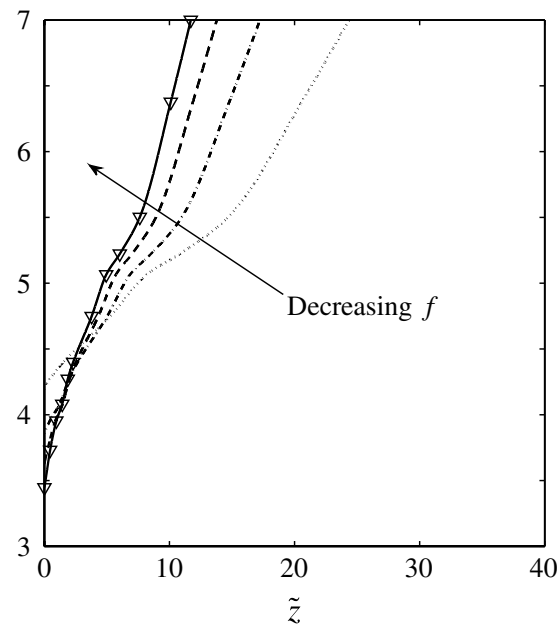

FIGURE 12. Estimating the effect of dilution prior to a vertical discharge into $(a)$ River Thames and $(b)$ Brighton Marina water. If the nozzle diameter remains unchanged then increasing the dilution prior to discharge has an inverse effect on $\Gamma_{0}$. The solid, dashed, dash-dot and dotted lines correspond to $f=0,25,50,75 \%$ and $\Gamma_{0}=4.78,2.02,0.60,0.08$. The symbols in $(a, b)$ match the experimentally determined values in figure 11 .

the discharge into seawater can be higher depending on how it is diluted (frequently various fluids such as engine cooling water are combined and discharged from one source).

Figure 12 shows the variation of the $\mathrm{pH}$ of an acidic discharge with distance when the wash-water has been diluted between 0 and $75 \%$, for $b_{0}=0.2 \mathrm{~m}$ and a discharge of $Q_{f}=0.015 \mathrm{~m}^{3} \mathrm{~s}^{-1}$ from the scrubber. The value of $Q_{0}=Q_{f}(1+f)$ increases proportionally to the additional dilution $(f)$ done prior to discharge. The relationship between $\mathscr{D}$ and $\hat{z}$ is determined by solving (2.19) numerically and relating the dilution factor to the $\mathrm{pH}$ in the plume. The initial dilution has an effect of increasing the initial $\mathrm{pH}$ but decreasing the gradient of the $\mathrm{pH}$ with distance. In this configuration, the vertical neutralization distances are so large that $\mathrm{pH}$ recovery would certainly need to be supplemented with the addition of an alkaline agent.

\section{Conclusion}

A mathematical model was developed to analyse the characteristics of a monoprotic acidic (a diprotic strong or weak acid is considered in the Appendix) jet or plume vertically injected into a stationary alkaline environment. Fundamentally, two processes were shown to be important: (a) dilution, caused by the mixing of acid with the alkaline ambient; and $(b)$ chemical reactions. In the case of a strong acid and a strong alkali that have fully dissociated, the alkali tended to mop up the excess hydrogen ions after mixing leading to a rapid reduction of the hydrogen ion concentration and a more rapid increase in the $\mathrm{pH}$ along the edges of the plume. At the point of neutralization the concentration of hydrogen ions and hydroxide ions is equal. A similar picture emerged for the case of a weak alkali where the hydroxide ions are only partially dissociated and as a result the $\mathrm{pH}$ showed a weaker dependence on the concentration of the alkali. 
To provide support for our models, experiments on both the chemistry and fluid mechanical aspects were conducted. The chemistry model is consistent with the titration measurements. As was expected, for mixtures of strong acid and strong alkali, the $\mathrm{pH}$ changed rapidly around the point of neutralization. In contrast to the usual titration studies where the volume of fluid used for titration is often small, we examined dilute strong alkalis where the $\mathrm{pH}$ changed much more slowly through the point of neutralization and the volume of the alkali was significant. Titrating a strong acid against distilled water shows that the $\mathrm{pH}$ rose by 1 unit when the acid was diluted by a factor of 10 , except close to neutralization where the dissociation of $\mathrm{H}_{2} \mathrm{O}$ is important.

The variation of the $\mathrm{pH}$ with distance from the outlet was examined using litmus indicator dye that was first calibrated against $\mathrm{pH}$. The neutralization distance was measured from the colour component intensity variations along the centreline of the jet and plume. The measured neutralization distances (correcting for the alkalinity of the water) were consistent with the distances predicted by the analysis for a variety of acid and alkali combinations.

The results from this study were applied to provide predictions about the behaviour of strong acids when mixed with river and seawater. In this configuration, the $\mathrm{pH}$ as a function of distance, volume flux and discharge diameter were discussed. In the context of the environmental application to wet scrubber discharges from ships, when the ship is underway the discharges tend to be swept into the wake of the ship where dilution is extremely rapid. This alone will probably lead to the $\mathrm{pH}$ recovery even when the ambient fluid is freshwater. When a ship starts from rest or is in port, $\mathrm{pH}$ recovery occurs by both chemistry and dilution of the acid by entrainment. The engineering parameter which largely controls the $\mathrm{pH}$ recovery of a jet discharge is the diameter of the nozzle, where an initially small jet diameter significantly shortens the recovery distance. Since there are constraints on the exit flow rate (due to pressure head constraints and piping), halving the jet diameter (from 0.4 to $0.2 \mathrm{~m}$ ) halves the neutralization distance. Further work is focused on exploring the policy constraints on wet scrubber discharges.

\section{Acknowledgement}

The authors would like to thank J. Eames, University of Hull, for advice regarding the choice of chemicals.

\section{Appendix}

In this appendix we discuss the implications of a diprotic acid being injected into an alkaline environment. Diprotic acids are characterized by two dissociation constants that describe the ease of dissociation of the first and the second $\mathrm{H}^{+}$ion. The dissociations for aqueous weak/strong diprotic acid and weak/strong monoprotic alkali are

$$
\begin{aligned}
& \mathrm{H}_{2} \mathrm{~A} \rightleftharpoons \mathrm{HA}^{-}+\mathrm{H}^{+}, \\
& \mathrm{HA}^{-} \rightleftharpoons \mathrm{A}^{2-}+\mathrm{H}^{+}, \\
& \mathrm{MOH} \rightleftharpoons \mathrm{M}^{+}+\mathrm{OH}^{-} .
\end{aligned}
$$

The charge balance equation is

$$
\left[\mathrm{H}^{+}\right]+\left[\mathrm{M}^{+}\right]=\left[\mathrm{OH}^{-}\right]+\left[\mathrm{HA}^{-}\right]+2\left[\mathrm{~A}^{2-}\right] .
$$



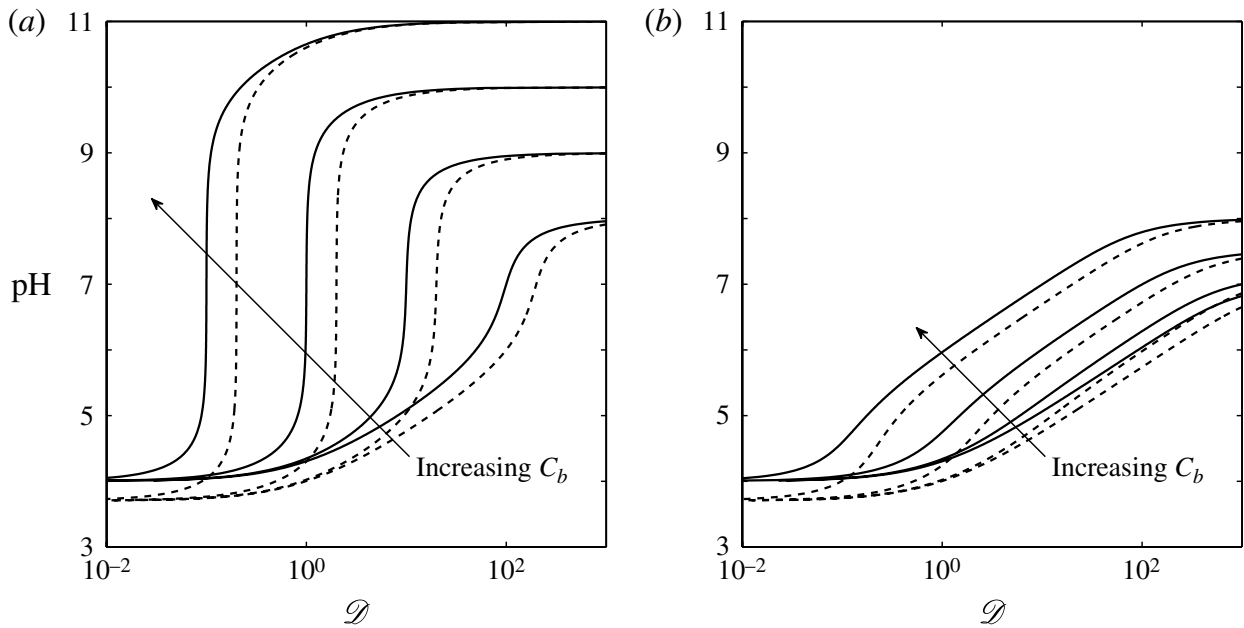

FIGURE 13. The $\mathrm{pH}$ of the jet or plume is plotted for four cases corresponding to $(a)$ strong acid-strong alkali or $(b)$ strong acid-weak alkali reaction. The solid line is for nitric acid and corresponds to (2.4) while the dashed line is for sulphuric acid and corresponds to (A 7).

The dissociation constants for a weak/strong diprotic acid and a weak/strong monoprotic alkali are

$$
K_{a 1}=\frac{\left[\mathrm{H}^{+}\right]\left[\mathrm{HA}^{-}\right]}{\left[\mathrm{H}_{2} \mathrm{~A}\right]}, \quad K_{a 2}=\frac{\left[\mathrm{H}^{+}\right]\left[\mathrm{A}^{2-}\right]}{\left[\mathrm{HA}^{-}\right]}, \quad K_{b}=\frac{\left[\mathrm{M}^{+}\right]\left[\mathrm{OH}^{-}\right]}{[\mathrm{MOH}]} .
$$

The expressions for mass conservation of the acid and the alkali are

$$
C_{a}^{0} V_{a}=\left(V_{a}+V_{b}\right)\left(\left[\mathrm{H}_{2} \mathrm{~A}\right]+\left[\mathrm{HA}^{-}\right]+\left[\mathrm{A}^{2-}\right]\right), \quad C_{b}^{0} V_{b}=\left(V_{a}+V_{b}\right)\left([\mathrm{MOH}]+\left[\mathrm{M}^{+}\right]\right) .
$$

Combining all of the above into an expression if dilution

$$
\frac{V_{b}}{V_{a}}=\frac{\left(C_{a}^{0}\left(K_{a 1}\left[\mathrm{H}^{+}\right]+2 K_{a 1} K_{a 2}\right)\right) /\left(\left[\mathrm{H}^{+}\right]^{2}+K_{a 1}\left[\mathrm{H}^{+}\right]+K_{a 1} K_{a 2}\right)-\left[\mathrm{H}^{+}\right]+K_{w} /\left[\mathrm{H}^{+}\right]}{C_{b}^{0} /\left(1+K_{w} /\left(\left[\mathrm{H}^{+}\right] K_{b}\right)\right)+\left[\mathrm{H}^{+}\right]-K_{w} /\left[\mathrm{H}^{+}\right]}=\mathscr{D} .
$$

The titration curves from (A 7) for sulphuric acid $\left(K_{a 1}=1 \mathrm{~mol} \mathrm{l}^{-1} ; K_{a 2}=1.2 \times\right.$ $10^{-2} \mathrm{~mol} \mathrm{l}^{-1}$ ) are plotted in figure 13 .

\section{REFERENCES}

Atkins, P. W. \& De Paula, J. 2006 Atkins' Physical Chemistry. Oxford University Press.

Behrends, B., Liebezeit, G. \& Hufnagl, M. 2005 Effects on Seawater Scrubbing. BP Marine/Research Centre Terramare.

Bell, H. L. \& NebeKer, A. V. 1969 Preliminary studies on the tolerance of aquatic insects to low pH. J. Kansas Entomol. Soc. 42, 230-236.

Bisset, D. K., Hunt, J. C. R. \& Rogers, M. M. 2002 The turbulent/non-turbulent interface bounding a far wake. J. Fluid Mech. 451, 383-410.

Blatcher, D. J. \& EAmes, I. 2013 Compliance of Royal Navy ships with nitrogen oxide emissions legislation. Mar. Pollut. Bull. 74, 10-18.

Brønsted, J. N. 1923 Some remarks on the concept of acids and bases. Rec. Trav. Chim. 42, 718-728. 
CAmpbell, A. N. \& CARdoso, S. S. S. 2010 Turbulent plumes with internal generation of buoyancy by chemical reaction. J. Fluid Mech. 655, 122-151.

CArdoso, S. S. S. \& MCHugh, S. T. 2010 Turbulent plumes with heterogeneous chemical reaction on the surface of small buoyant droplets. J. Fluid Mech. 642, 49-77.

Conroy, D. T. \& Llewellyn-SMith, G. 2008 Endothermic and exothermic chemically reacting plumes. J. Fluid Mech. 612, 291-310.

Corriveau, A. F. \& Baines, W. D. 1993 Diffusive mixing in turbulent jets as revealed by a pH indicator. Exp. Fluids 16, 129-136.

Da Silva, C. B., Hunt, J. C. R., Eames, I. \& Westerweel, J. 2014 Interfacial layers between regions of different turbulence intensity. Annu. Rev. Fluid Mech. 46, 567-590.

Dimotakis, P. E. \& Brown, G. L. 1976 The mixing layer at high Reynolds number: large-structure dynamics and entrainment. J. Fluid Mech. 78, 535-560.

DREVER, J. I. 1988 The Geochemistry of Natural Waters. Prentice-Hall.

EIGEN, M. 1954 Methods for investigation of ionic reactions in aqueous solutions with half-times as short as $10^{-9}$ sec. Discuss. Faraday Soc. 17, 194-205.

Frankignoulle, M. 1994 A complete set of buffer factors for acid/base $\mathrm{CO}_{2}$ system in seawater. J. Mar. Syst. 5, 111-118.

Gordus, A. A. 1985 Theory and Problems of Analytical Chemistry. McGraw-Hill.

Hansen, J. \& Nazarenko, L. 2004 Soot climate forcing via snow and ice albedos. Proc. Natl Acad. Sci. USA 101 (2), 423-428.

Hunt, J. C. R., Eames, I., Da Silva, C. B. \& Westerweel, J. 2011 Interfaces and inhomogeneous turbulence. Phil. Trans. A Math. Phys. Engng Sci. 369, 811-832.

Hunt, J. C. R., EAmes, I. \& Westerweel, J. 2006 Mechanics of inhomogeneous turbulence and interfacial layers. J. Fluid Mech. 554, 499-519.

Hunt, G. R. \& KAYE, N. G. 2001 Virtual origin correction for lazy turbulent plumes. J. Fluid Mech. 435, 377-396.

Hunt, G. R. \& KAYE, N. B. 2005 Lazy plumes. J. Fluid Mech. 533, 329-338.

JACOBSON, M. Z. 2010 Short-term effects of controlling fossil-fuel soot, biofuel soot and gases, and methane on climate, Arctic ice, and air pollution health. J. Geophys. Res. 115 (D14), D14209.

JIRKA, G. H. 2004 Integral model for turbulent buoyant jets in unbounded stratified flows. Part I. Single round jet. Environ. Fluid Mech. 4, 1-56.

Kaminski, E., TAit, S. \& CARAZzO, G. 2005 Turbulent entrainment in jets with arbitrary buoyancy. J. Fluid Mech. 526, 361-376.

KAYe, N. B. \& Linden, P. F. 2004 Coalescing axisymmetric turbulent plumes. J. Fluid Mech. 502, $41-63$.

KitamuRA, Y. \& ITOH, T. 1987 Reaction volume of protonic ionization for buffering agents. Prediction of pressure dependence on $\mathrm{pH}$ and pOH. J. Sol. Chem. 16, 715-725.

LIST, E. J. 1982 Turbulent jets and plumes. Annu. Rev. Fluid Mech. 14 (1), 189-212.

LOWry, T. M. 1923 The uniqueness of hydrogen. Chem. Ind. 42, 43-47.

Morton, B. R. 1959 Forced plumes. J. Fluid Mech. 5, 151-163.

Morton, B. R., TAYlor, G. \& TURner, J. S. 1956 Turbulent gravitational convection from maintained and instantaneous sources. Proc. R. Soc. Lond. 234A, 1-23.

Prandtl, L. 1954 Essentials of Fluid Mechanics. Blackie.

Raven, J., Caldeira, K., Elderfield, H., Hoegh-Guldberg, O., Liss, P., Riebesell, U., Shepherd, J., Turley, C. \& Watson, A. 2005 Ocean Acidification due to Increasing Atmospheric Carbon Dioxide. The Royal Society: the Science Policy Section.

Scase, M. M., Caulfield, C. P. \& Dalziel, S. B. $2006 a$ Boussinesq plumes and jets with decreasing source strengths in stratified environments. J. Fluid Mech. 563, 463-472.

Scase, M. M., Caulfield, C. P., Dalziel, S. B. \& Hunt, J. C. R. $2006 b$ Time-dependent plumes and jets with decreasing source strengths. J. Fluid Mech. 563, 443-461.

SCHINDLER, D. W. 1988 Effects of acid rain on freshwater ecosystems. Science 239 (4836), $149-157$. 
SøREnsen, S. P. L. 1909 Enzymstudien II. Uber die messung und die bedeutung der wasserstoffionenkonzentration bei enzymatischen prozessen. Biochem. Zeit. 21, 131-200.

Trent, L. L., Hestand, R. S. III \& Carter, C. C. 1978 Toxicity of sulfuric acid to aquatic plants and organisms. J. Aquat. Plant Manage 16, 40-43.

TUrner, J. S. 1969 Buoyant plumes and thermals. Annu. Rev. Fluid Mech. 1, 29-44.

Westerweel, J., Fukushima, C., Pedersen, J. M. \& Hunt, J. C. R. 2005 Mechanics of the turbulent-nonturbulent interface of a jet. Phys. Rev. Lett. 95, 174501.

Westerweel, J., Fukushima, C., Pedersen, J. M. \& Hunt, J. C. R. 2009 Momentum and scalar transport at the turbulent/non-turbulent interface of a jet. J. Fluid Mech. 631, 199-230.

Woods, A. W. 1997 A note on non-Boussinesq plumes in an incompressible stratified environment. J. Fluid Mech. 345, 347-356.

Woods, A. W. 2010 Turbulent plumes in nature. Annu. Rev. Fluid Mech. 42, 391-412. 